\title{
UTILIZAÇÃO DA METODOLOGIA DA ESTRELA DECISÓRIA E DA MATRIZ BASICO PARA MELHORIA DA GESTÃO DE ESTOQUE EM UMA EMPRESA VAREJISTA DE MATERIAIS DE CONSTRUÇÃO
}

\author{
Diandria Oliveira da Silva (UNIGRANRIO) diandria.silva@outlook.com \\ Karen Leal Agostinho (UNIGRANRIO) karenleal1@bol.com.br \\ Nathália Campos de Oliveira (UNIGRANRIO) nathaliacampos3@unigranrio.br \\ Marcos dos Santos (Instituto Militar de Engenharia) marcosdossantos_doutorado_uff@yahoo.com.br
}

\section{Resumo}

As empresas varejistas ganharam força mundialmente, tornando-se grandes no Brasil em diversos ramos varejistas. A deficiência na gestão de estoque afeta diferentes áreas e é comum nas empresas de grande porte, nas quais muitas chegam a falir por tomarem ações inadequadas. É necessário buscar uma gestão eficiente de seus recursos para atender melhor os seus clientes, sobressaindo-se perante seus concorrentes. $\mathrm{O}$ presente trabalho visa demonstrar os resultados obtidos após a utilização da metodologia da Estrela Decisória através de um estudo de caso aplicado em uma empresa de Materiais de Construção localizada em Nova Iguaçu - RJ, com o objetivo de reduzir a quantidade gerada por materiais obsoletos no estoque com mais de 90 dias sem giro, acarretando grande prejuízo financeiro a empresa. Após a pesquisa, foi possível verificar que obter uma conferência periódica de estoque, realizar um treinamento para tornar os gerentes mais capacitados e organizar o planejamento de compras, permite a empresa reduzir o custo de capital parado pelo excesso de materiais obsoletos no estoque.

Palavras-Chaves: Empresa do Varejo; Material de Construção; Matriz BASICO; Estrela Decisória.

\section{Introdução}

Uma empresa de grande porte na área de materiais e construção situada no Rio de Janeiro, dado nome fictício como "Constrular", atravessa um grande problema na área de gestão de estoque ao realizar e controlar os pedidos de compra dos produtos, causando retrabalho e uma grande carência de verificação decorrente da falta de capacidade do funcionário responsável em efetuar os procedimentos necessários para que todos os produtos que entram e saem da loja estejam corretos e compatíveis com a demanda do cliente, comprometendo o faturamento e as operações da empresa. É essencial tomar medidas corretas e eficazes para que não haja custos excessivos gerados por produtos obsoletos e prejuízos na empresa. 
As empresas varejistas ganharam força mundialmente, tornando-se grandes no Brasil em diversos ramos varejistas. A deficiência na gestão de estoque de produtos afeta diversas áreas e é comum nas empresas de grande porte, nas quais muitas chegam a falir por tomarem ações inadequadas. O grande desafio do gestor é saber quando e quanto de material deve ser necessário para manter no estoque sem que haja falta ou excesso, devido a grande variedade de itens e diferentes padrões de demanda. Para se destacar e garantir a fidelidade dos clientes é de mera importância ter qualidade no serviço e foco na redução dos custos, é preciso orientação para lidar com o cliente e eficiência na parte operacional. Especialmente no varejo, onde é visível o prejuízo na qualidade dos serviços prestados, afetando diretamente no atendimento, pois a disponibilidade do produto é essencial para que ocorra a venda e a satisfação dos clientes, que sempre esperam o melhor e exigem níveis de serviços altos e preços acessíveis conforme a qualidade do produto.

Segundo Amaro (2018), o conceito da gestão de estoque está diretamente relacionado com a necessidade de interação das áreas associadas à área de estoque, como por exemplo, o departamento de compras e os fornecedores. Dessa forma uma gestão bem realizada contribui de forma prática e positiva para todos os envolvidos nessa cadeia.

Os estoques incorrem em custos, oneram o capital, ocupam espaço e necessitam de gerenciamento tanto na entrada como na saída. Um dos grandes desafios enfrentados atualmente pelos administradores das empresas, independente do porte se refere ao equilíbrio dos estoques com a demanda. $\mathrm{O}$ sucesso ou fracasso de muitas organizações encontra-se através da gestão de estoque, que é constituída por administração de materiais, recursos humanos e financeiros.

\section{Descrição do problema}

Ter materiais de pronta entrega e que atendam seus clientes rapidamente, não apenas gera credibilidade, como também aumenta as vantagens em relação à concorrência, porém quando esse estoque não consegue obter giro a mais de 90 dias, acaba gerando prejuízos e causando obsolescência de materiais na empresa estudada.

Atualmente, a empresa estudada realiza o seu trabalho com alto índice de desperdícios gerado por produtos obsoletos devido à falta de procedimentos na execução de tarefas, e encontra dificuldades em atender as demandas dos clientes. Então, para que a empresa se mantenha no mercado extremamente competitivo, deverá desfrutar das melhores estratégias. Uma delas 
será eliminar o desperdício gerado por obsoletos, para aperfeiçoar o processo de compra. Após uma análise foram encontrados os seguintes problemas:

- Produtos fora da área de vendas - Foi encontrada grande quantidade de produtos nos aéreos das lojas, os mesmos que nunca chegaram a ir para a área de vendas, perdendo a chance de qualquer saída do produto.

- Produtos sem mostruários - Foi encontrada uma variedade de produtos na área de vendas em caixas lacradas jamais expostas, inibindo qualquer possibilidade de venda, pois em caixas lacradas se torna impossível a sua visualização tanto para vendedores como clientes.

- Embalagens avariadas - Foi encontrado um número significativo de embalagens danificadas de produtos com marcas, arranhões e manchas, dificultando sua venda, pois não consegue ter saída pelo fato do cliente ter receio do produto estar danificado.

- Compra do mesmo produto - O setor de compras continua fazendo compras dos mesmos produtos que estão com baixo giro, gerando mais excesso de estoque de produtos caros que não estão tendo saída.

- Falta de análise de giro - Ao analisar o giro dos estoques e consequentemente os itens que estavam obsoletos, foi verificado que uma grande parte das compras feitas são alocadas em lojas erradas na rede e sem a devida atenção, visto o seu baixo giro e volume de itens parados, o que leva a empresa a ter uma grande quantidade de recursos financeiros parados em estoque.

- Falta de controle de giro de vendas - Somente quando estão a mais de 90 dias que a empresa observa que o produto se tornou obsoletos, não conseguindo entrar com um plano de ação a tempo para a venda.

- Preço não compatível com os concorrentes - Foi analisado que a empresa possui o preço mais alto que seus concorrentes, até mesmo em relação aos produtos que já entraram como obsoletos, impedindo assim a saída do mesmo, pois o cliente além de qualidade procura o menor preço. 
A Figura 1 apresenta um mapa mental com as condições de contorno do problema estudado:

Figura 1 - Mapa Mental do problema estudado

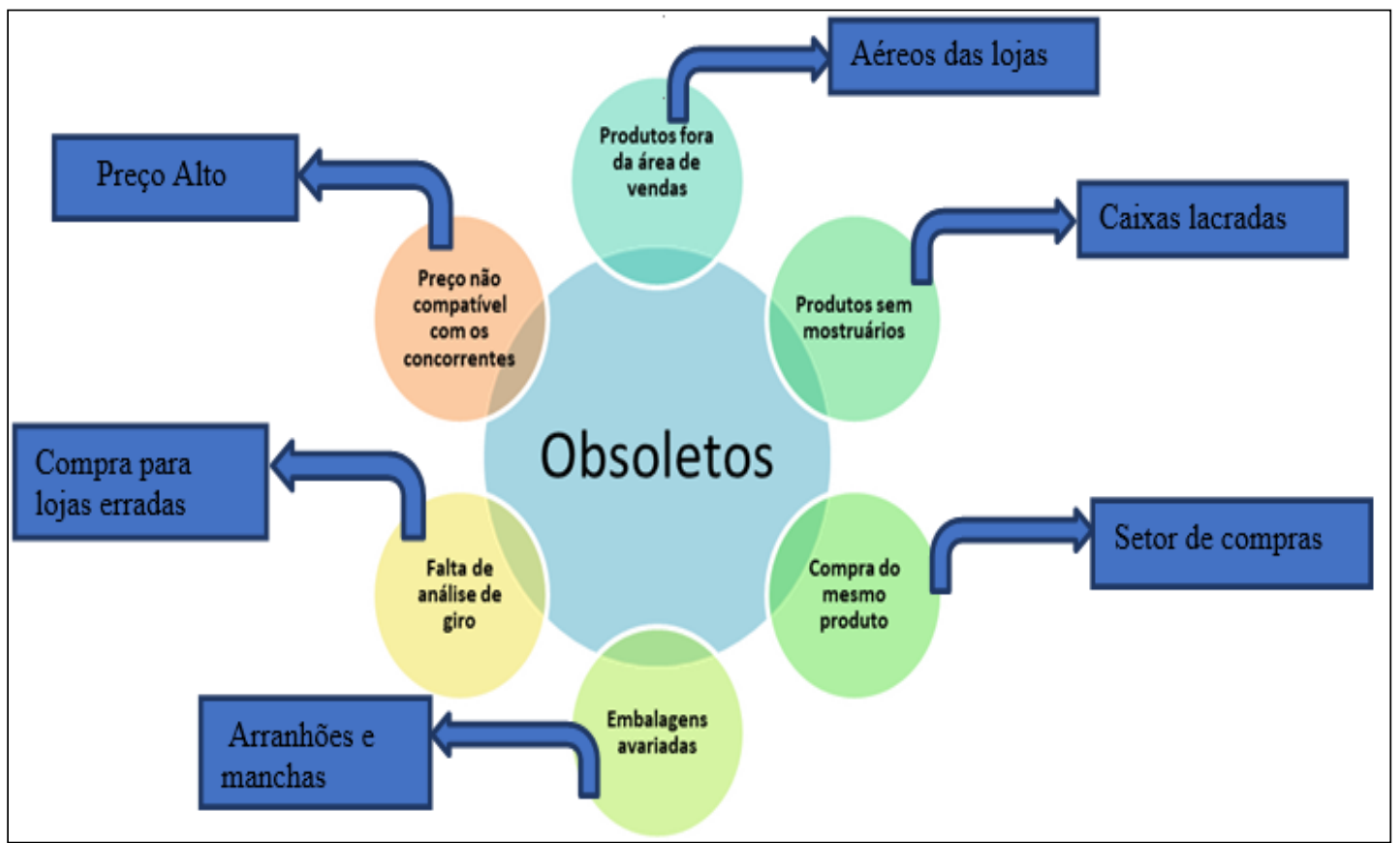

Fonte: Autores (2019)

Sendo assim este estudo lança o seguinte questionamento: de que forma a gestão do controle de estoque pode contribuir para reduzir a quantidade de itens obsoletos?

\section{Fundamentação teórica}

\subsection{Gestão de estoque}

Fernandes et al (2016), afirma que em um mundo que está em constante mudança, os custos gerados pela obsolescência de materiais estocados afetam de forma cada vez mais significativa as empresas. Com a evolução tecnológica, os produtos ficam obsoletos em um curto período de tempo, acarretando na impossibilidade de recuperar o investimento realizado em estoque.

\subsection{Ferramentas da qualidade}

As ferramentas de qualidade são técnicas que tem o propósito de medir, analisar e propor soluções para todos os problemas que possam aparecer e interferir no bom desempenho de todo o processo de trabalho.

Os métodos de melhoria da qualidade existentes são amplamente utilizados em empresas de todos os portes e ramos, como também dentro de qualquer área, incluindo planejamento de 
engenharia, manufatura, finanças, contabilidade, marketing e assistência técnica. (MONTGOMERY, 2016).

É sabido que existem diversas ferramentas da qualidade, mas essa pesquisa irá focar no entendimento das ferramentas: Brainstorming, Curva ABC, Diagrama de Causa e Efeito, Matriz Basico, Ciclo PDCA, Estrela Decisória e 5W2H.

\subsubsection{Brainstorming}

Este tipo de ferramenta é conhecido como " tempestades de ideias", tem por finalidade obter o maior número possível de sugestões, que vão servir futuramente para realizar um processo de julgamento e de análise das sugestões que forem obtidas. (CABRAL; ZEITOUNI e SOUZA, 2017).

Santos (2017) reforça que o brainstorming é utilizado quando são necessárias respostas rápidas a questões relativamente simples, mostrando ser uma técnica popular e eficaz.

\subsubsection{Curva ABC}

A curva ABC, também conhecida como princípio de Pareto ou principio 80/20, surgiu na Itália por volta de 1897 e foi elaborada por Vilfredo Pareto, após anos de estudos sobre a distribuição de renda e riqueza sobre a população local. No entanto, Pareto observou neste estudo que a renda total se concentrava, em maior porcentagem nas mãos de uma pequena parte da população, aproximadamente $80 \%$ e $20 \%$, ou seja, $20 \%$ das pessoas controlavam $80 \%$ das riquezas. (POZO 2007).

Seguindo o princípio de Pareto, os itens são classificados em três categorias A, B e C. Na classificação $\mathrm{ABC}$ os itens que merecem maior atenção são os itens de classe $\mathrm{A}$, pois apesar de representarem quantidades menores, possuem o maior valor em estoque, ficando com $80 \%$ do valor total.

\subsubsection{Diagrama de Causa e Efeito}

O diagrama de Causa e Efeito ou Diagrama de Ishikawa, também recebe o nome de Diagrama Espinha de Peixe pelo seu formato gráfico.

Já Carpinetti (2010) afirma que o mesmo foi apresentado com o intuito de estabelecer as relações que existem entre um problema ou o efeito inesperado do resultado de um processo e todas as possíveis causas desse problema, atuando como um direcionador para a descoberta da causa predominante deste problema, e para a análise das medidas corretivas que deverão ser adotadas. 


\subsubsection{Matriz BASICO}

Oliveira, Santos e Martins (2019) apontam que o atributo B (Benefícios) se refere ao impacto da solução analisada nos resultados do processo, como: redução de custos gerada, aumento na produção e redução dos defeitos. Já o atributo A (Abrangência) aborda o montante da organização (integrantes) que será beneficiado com a melhoria do processo em questão. A Satisfação (S) do cliente interno corresponde ao grau de satisfação a ser gerado nos integrantes da organização que têm alguma relação com o processo cuja melhoria está sendo estudada. Os Investimentos (I) requeridos consideram o montante dos recursos que serão necessários para a efetivação da melhoria do processo em questão. O Cliente (C) externo satisfeito compreende o impacto que a melhoria do processo em questão terá sobre o cliente externo. Por fim, a Operacionalização (O) significa a exequibilidade da melhoria do processo em estudo, levando em conta aspectos como: resistência à mudança, impedimentos de ordem social/cultural/legal, domínio da tecnologia requerida para tal, simplicidade da implantação e facilidade de uso dos pontos fortes da organização.

\subsubsection{Ciclo PDCA}

O ciclo PDCA, também conhecido como ciclo de Deming, foi introduzido no Japão após a guerra, e divulgado por Deming em 1950 que foi quem efetivamente o aplicou. O método é utilizado pelas organizações para gerenciar os seus processos internos e forma a garantir o alcance de metas estabelecidas, tomando as decisões como fator de direcionamento das decisões.

Com base nesta análise e comparando as ações com o esboço, o gestor inicia assim, a implantação de medidas para checagem das falhas que surgiram no processo ou produto. $\mathrm{O}$ Ciclo PDCA é dividido em quatro etapas. A Figura 2 mostra as etapas deste ciclo.

Figura 2 - Ciclo PDCA

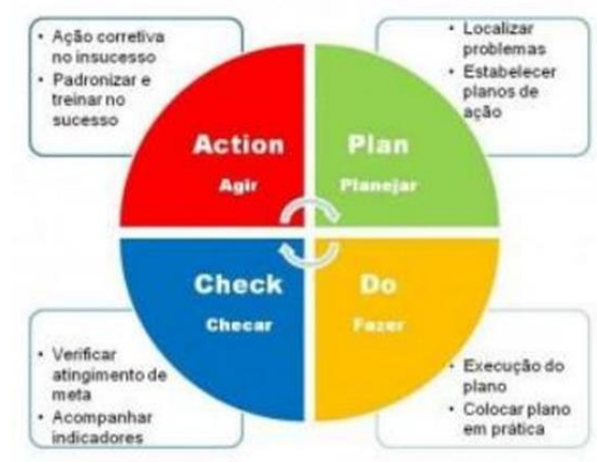

Fonte: Periard (2011) 


\subsubsection{Estrela Decisória}

A Estrela Decisória determina uma sequência lógica de passos, de forma que a solução de um problema progrida racionalmente, esgotando cada etapa anterior, que atua como pré-requisito para a etapa seguinte. É como uma escada de oito degraus, que permite a subida até o último degrau, alcançando objetivo de solucionar o problema com a melhor combinação de eficácia e eficiência, como mostra a Figura 3.

Figura 3 - Passos da Estrela Decisória

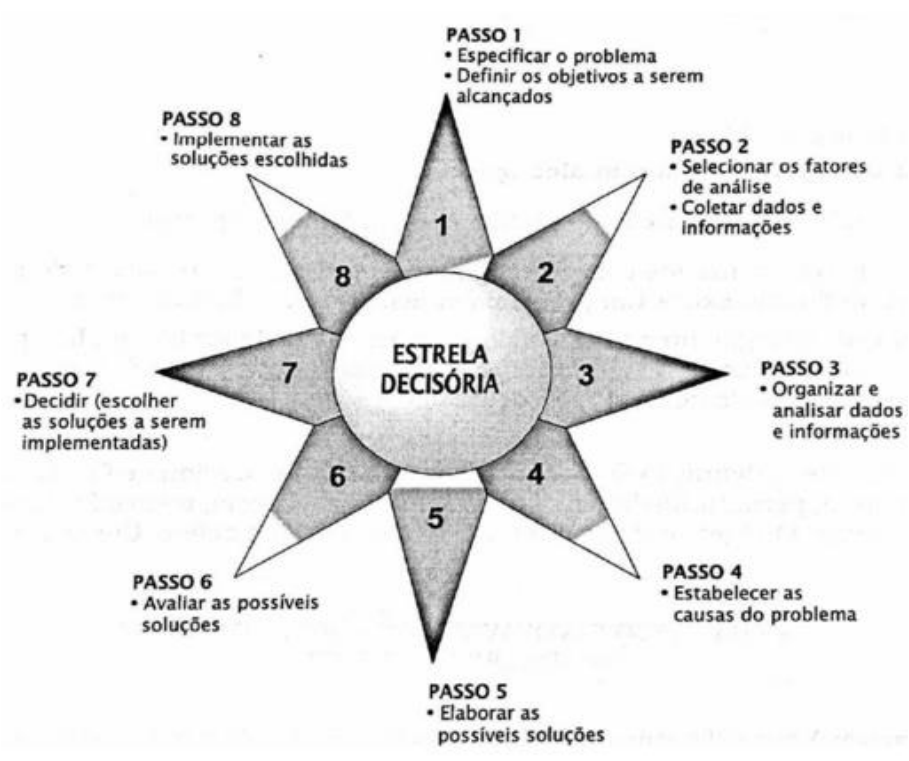

Fonte: Maranhão e Macieira (2010)

\subsubsection{W2H}

Arruda et al (2016), define que esta ferramenta é empregada como base para a implantação de melhoramento nos processos das organizações, e analisar os problemas e planejar as ações corretivas, com os seguintes questionamentos, que tem como origem as palavras em inglês, como: Why(Por quê?), What(O que?), Who (Quem?), When(Quando?), Where(Onde?), How(Como?) e HowMuch(Quanto?).

Este método é uma ferramenta que permite, a todo o momento, identificar dados importantes de um projeto, obtém-se sete perguntas para serem implementadas e propor soluções vantajosas, disposta no quadro abaixo (LISBOA; GODOY, 2012).

\section{Estudo de caso}

\subsection{Proposta de solução}

Diante da grande necessidade de mudar a realidade em que a empresa se encontra será utilizada a metodologia da Estrela Decisória para chegar a soluções do presente problema, e 
juntamente com a Matriz BASICO analisar a melhor solução a ser tomada através da priorização que a mesma realiza. Para o plano de ação será proposto uma implementação do 5W2H para se obter um processo de gestão mais ágil na execução de tarefas da empresa. A Figura 4 retrata a sequência das ferramentas que serão utilizadas na Estrela Decisória do presente estudo.

Figura 4 - Passos da proposta de solução

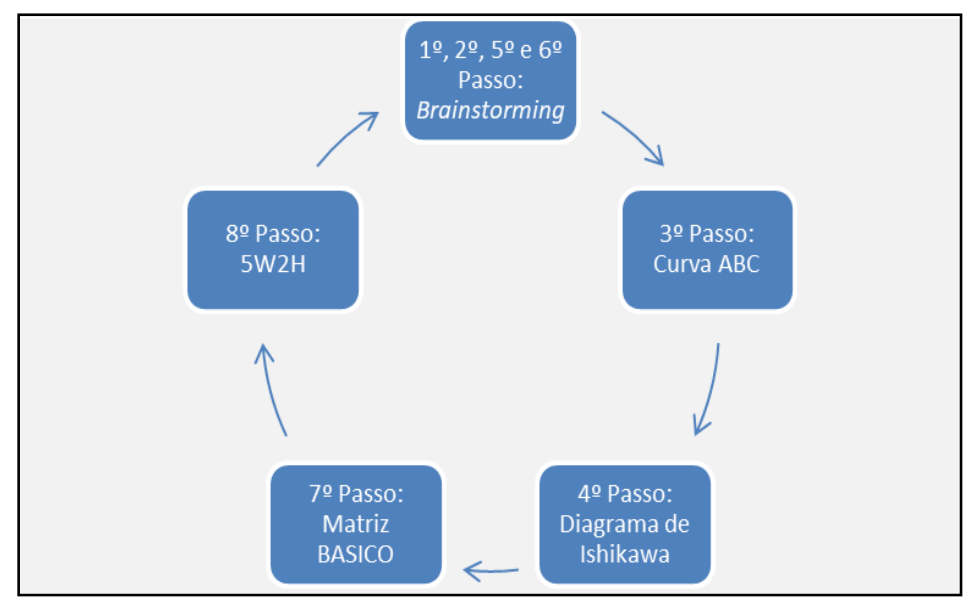

Fonte: Autores (2019)

\subsection{Aplicação do Método da Estrela Decisória}

A Estrela Decisória determina uma sequência lógica de passos, de forma que a solução de um problema progrida racionalmente, esgotando cada etapa anterior, que atua como pré-requisito para a etapa seguinte. É como uma escada de oito degraus, que permite a subida até o último degrau, alcançando o objetivo de solucionar o problema com a melhor combinação de eficiência e eficácia.

\section{$1^{\circ}$ Passo: Definir os objetivos a serem atingidos}

Foram realizados acompanhamentos e reuniões entre os colaboradores, onde foi efetuada a observação direta da empresa com o uso do brainstorming, a partir desta ferramenta auxiliar da qualidade foram levantadas as possíveis ocorrências de problemas como falta de qualificação profissional, deficiência na organização e gestão de estoque, falta de planejamento de compras, como também foram relatados que a maioria dos materiais é estocada de forma não organizada e com uma má distribuição no espaço físico que há na empresa assim que são entregues, a maioria dos materiais são armazenados aleatoriamente ou onde existir um espaço disponível para alocação, sem um lugar específico para cada tipo de material. 


\section{$2^{\circ}$ Passo: Coletar dados e Informações}

Com base no levantamento de opiniões através de visitas técnicas na empresa estuada foi possível ter acesso ao estado atual dos produtos tratados como obsoletos pela empresa e suas quantidades, como mostra na Tabela 1, o excesso de estoque encontrado no presente setor:

Tabela 1 - Quantidade de obsolescência e itens no estoque durante 6 meses

\begin{tabular}{|c|c|c|c|}
\hline Mês & $\begin{array}{l}\text { Quantidade total } \\
\text { em estoque. }\end{array}$ & $\begin{array}{c}\text { Itens } \\
\text { Obsoletos (uni). }\end{array}$ & $\begin{array}{l}\text { Giro total de } \\
\text { obsoletos dos } \\
\text { últimos 6 meses. }\end{array}$ \\
\hline $01 / 2019$ & 256 & 110 & 6 \\
\hline $02 / 2019$ & 230 & 115 & 5 \\
\hline $03 / 2019$ & 220 & 100 & 10 \\
\hline $04 / 2019$ & 210 & 120 & 22 \\
\hline $05 / 2019$ & 200 & 192 & 8 \\
\hline $06 / 2019$ & 195 & 170 & 25 \\
\hline
\end{tabular}

Fonte : Autores (2019)

Diante deste quadro de obsolescência e de acordo com as reuniões e entrevistas aplicadas com os colaboradores, foi relatada que a grande dificuldade encontrada, é a ausência de conhecimento relacionada à gestão da empresa. Com isso o planejamento de compras e o controle de estoque são afetados, pois eles não entendem como acontece o giro de produtos e a demanda dos clientes é essencial para determinar à hora certa de fazer um novo pedido. Outro problema apresentado é a exigência do mercado atual, que impõe para êxito nos negócios, gestores qualificados e experientes, a mesma relata que devido à desmotivação dos gestores, fica difícil buscar novos conhecimentos e aplicá-los.

Com base nas informações coletadas, foi possível realizar um quadro mais a fundo para entender melhor as origens dos problemas reais que a empresa vem enfrentando, como mostra o Quadro 1. 
Quadro 1 - Observação do problema

\begin{tabular}{||l|c|c|}
\hline \multicolumn{2}{||c|}{$\begin{array}{l}\text { Há problemas na gestão de Estoque e no planejamento de compras devido } \\
\text { á falta de conhecimento dos gestores e escolaridade devido á / por: }\end{array}$} \\
\hline \hline \multicolumn{2}{|c|}{ Motivos } & Não \\
\hline $\begin{array}{l}\text { O gestor possui outro trabalho que reduz o tempo de } \\
\text { dedicação à empresa. }\end{array}$ & $\mathrm{X}$ \\
\hline A cultura da empresa está adaptada ao cenário atual. & $\mathrm{X}$ & $\mathrm{X}$ \\
\hline Falta de capacitação do quadro de pessoal. & $\mathrm{X}$ & \\
\hline Dificuldade na elaboração do planejamento de compras. & $\mathrm{X}$ & \\
\hline Dificuldade em aplicar técnicas de gestão de estoque. & $\mathrm{X}$ & \\
\hline Dificuldade em equilibrar estoque e compra & $\mathrm{X}$ & \\
\hline Desmotivação e insatisfação com seus funcionários. & & \\
\hline
\end{tabular}

Fonte: Autores (2019)

Diante dessa situação, Santos et al (2017) afirma que a gestão de estoques de uma empresa deve ser bem estruturada para que não ocorram falta de produtos estratégicos e a mesma deve prezar para que os estoques custem o mínimo possível para a organização.

\section{$3^{\circ}$ Passo: Organizando e analisando os dados}

Para efeito de amostra, foram utilizados os itens com maiores quantidades de obsoletos do setor de metais da empresa durante 12 meses e elaborou-se a curva ABC do estoque por categoria de produtos, considerando para efeito de classificação, para que se separem os itens de maior importância ou impacto, os quais normalmente são em menor número.

Para realização desta análise utilizou-se as seguintes considerações:

- Foram contabilizados apenas os produtos que estiveram a mais de 90 dias sem giro, já considerados obsoletos no período de análise.

- Buscou-se o agrupamento dos itens conforme o preço real de cada unidade, para a simplificação da análise como mostra na Tabela 2. 
Tabela 2 - Classificação dos materiais obsoletos no estoque

\begin{tabular}{|c|c|c|c|c|c|c|c|c|}
\hline \multirow{2}{*}{\begin{tabular}{|c|} 
Item/Material \\
Monocomando DOC PT \\
\end{tabular}} & \multirow{2}{*}{\begin{tabular}{|c|}
$\begin{array}{c}\text { Quant.Ultiliza } \\
\text { da }\end{array}$ \\
33 \\
\end{tabular}} & \multicolumn{2}{|c|}{$\begin{array}{c}\text { Valor Unitario } \\
\text { R\$\$ } \\
\end{array}$} & \multicolumn{2}{|c|}{ Valor Total } & \multirow{2}{*}{$\begin{array}{c}\begin{array}{c}\text { Porcentagem } \\
\text { individual }\end{array} \\
34,15 \% \\
\end{array}$} & \multirow{2}{*}{$\begin{array}{c}\begin{array}{c}\text { Porcentagem } \\
\text { Acumulada }\end{array} \\
34,15 \% \\
\end{array}$} & \multirow{2}{*}{$\frac{\text { Classificação }}{A}$} \\
\hline & & $\mathrm{R} \$$ & $3.200,00$ & $\mathrm{RS}$ & $105.600,00$ & & & \\
\hline Monocomando DOC VM & 29 & $\mathrm{RS}$ & $3.400,00$ & $\mathrm{R} \$$ & $98.600,00$ & $31,89 \%$ & $66,04 \%$ & A \\
\hline Torneira DOC PT & 18 & $\mathrm{R} \$$ & $1.800,00$ & $\mathrm{R} \$$ & $32.400,00$ & $10,48 \%$ & $76,51 \%$ & A \\
\hline Misturador Oasis & 20 & $\mathrm{R} \$$ & 972,00 & $R \$$ & $19.440,00$ & $6,29 \%$ & $82,80 \%$ & B \\
\hline Chuveiro Bonaducha & 10 & $\mathrm{R} \$$ & 687,00 & $\mathrm{R} \$$ & $6.870,00$ & $2,22 \%$ & $85,02 \%$ & $B$ \\
\hline Torneira Breezy & 16 & $\mathrm{R} \$$ & 410,00 & $\mathrm{R} \$$ & $6.560,00$ & $2,12 \%$ & $87,14 \%$ & $B$ \\
\hline Acabamento Next & 67 & $\mathrm{R} \$$ & 97,00 & $\mathrm{R} \$$ & $6.499,00$ & $2,10 \%$ & $89,25 \%$ & $B$ \\
\hline Torneira Next & 13 & $\mathrm{R} \$$ & 400,00 & $\mathrm{R} \$$ & $5.200,00$ & $1,68 \%$ & $90,93 \%$ & $B$ \\
\hline Torneira Chess & 15 & $\mathrm{R} \$$ & 340,00 & $\mathrm{R} \$$ & $5.100,00$ & $1,65 \%$ & $92,58 \%$ & $B$ \\
\hline Torneira City & 10 & $\mathrm{R} \$$ & 480,00 & $\mathrm{R} \$$ & $4.800,00$ & $1,55 \%$ & $94,13 \%$ & $B$ \\
\hline Acabamento CHESS & 60 & $\mathrm{R} \$$ & 69,90 & $\mathrm{R} \$$ & $4.194,00$ & $1,36 \%$ & $95,48 \%$ & c \\
\hline Ducha fria Bonnaducha & 31 & $\mathrm{RS}$ & 121,00 & $\mathrm{R} \$$ & $3.751,00$ & $1,21 \%$ & $96,70 \%$ & c \\
\hline Acabamento Inova & 29 & $\mathrm{R} \$$ & 111,00 & $R \$$ & $3.219,00$ & $1,04 \%$ & $97,74 \%$ & c \\
\hline Acabamento Triplus & 42 & $\mathrm{RS}$ & 74,00 & $\mathrm{R} \$$ & $3.108,00$ & $1,01 \%$ & $98,74 \%$ & c \\
\hline Torneira Trio & 22 & $\mathrm{R} \$$ & 109,00 & $\mathrm{R} \$$ & $2.398,00$ & $0,78 \%$ & $99,52 \%$ & c \\
\hline Acabamento city & 13 & $\mathrm{RS}$ & 102,00 & $R \$$ & $1.326,00$ & $0,43 \%$ & $99,95 \%$ & c \\
\hline \multirow[t]{2}{*}{\begin{tabular}{|l|} 
Ducha Higiênica Chess \\
\end{tabular}} & 1 & $\mathrm{R} \$$ & 159,90 & $\mathrm{R} \$$ & 159,90 & $0,05 \%$ & $100,00 \%$ & c \\
\hline & & \multicolumn{2}{|c|}{ TOTAL } & $\mathrm{R} \$$ & $309.224,90$ & $100,00 \%$ & & \\
\hline
\end{tabular}

Fonte: Autores (2019)

Somando os itens A e B o volume de capital empregado é de $94,12 \%$ do total concentrados em 10 itens. Já no caso dos itens classificados como C o total do capital investido é de 5,87\% concentrados em 7 itens.

- A: Produtos com maior valor investido e menor quantidade de itens e que estão gerando prejuízos para empresa por seu alto valor parado em estoque.

- B: Itens de rotatividade intermediária não convêm manter estoque elevado.

- C: Produtos mais baratos e maior quantidade de itens, com o custo menor em relação aos demais.

A Figura 5 mostra a proporção do valor das classes A, B e C juntamente com a curva ABC:

Figura 5 - Curva $\mathrm{ABC}$

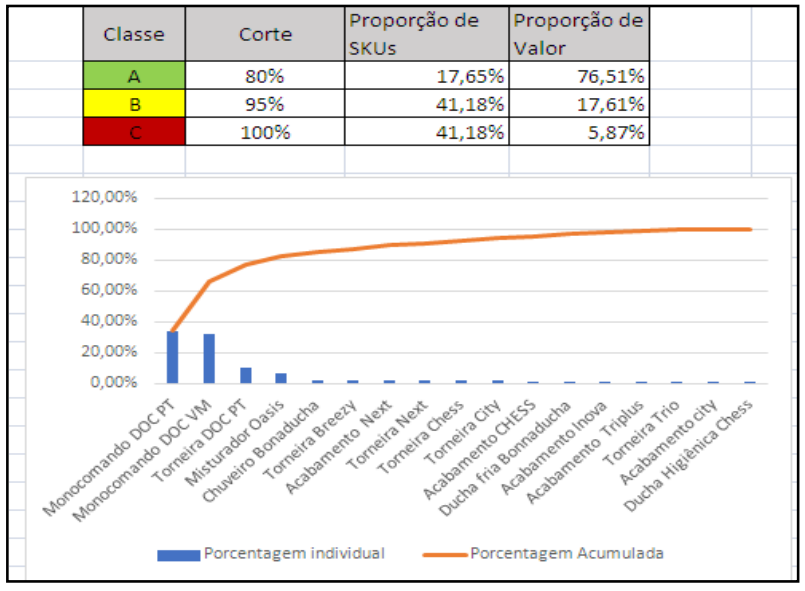

Fonte: Autores (2019) 
Através da curva $\mathrm{ABC}$, foi possível visualizar que a empresa precisa diminuir o que mais gera custo em obsolescência que são os itens de classe A (Monocomando e Torneiras) com 76,51\% de custo parado, onde é necessário tomar ações como realizar um planejamento de compras e ofertar os produtos que já estão obsoletos no estoque.

\subsection{4 $4^{\circ}$ Passo: Estabelecer as causas do problema}

Nesta etapa buscou-se ampliar a investigação das causas raízes do problema, para isso, utilizou-se a ferramenta Diagrama de Causa e Efeito, como também foi utilizado o brainstorming como ferramenta de apoio na construção do diagrama que é apresentado na Figura 6.

Figura 6 - Análise do problema estudado no cenário atual

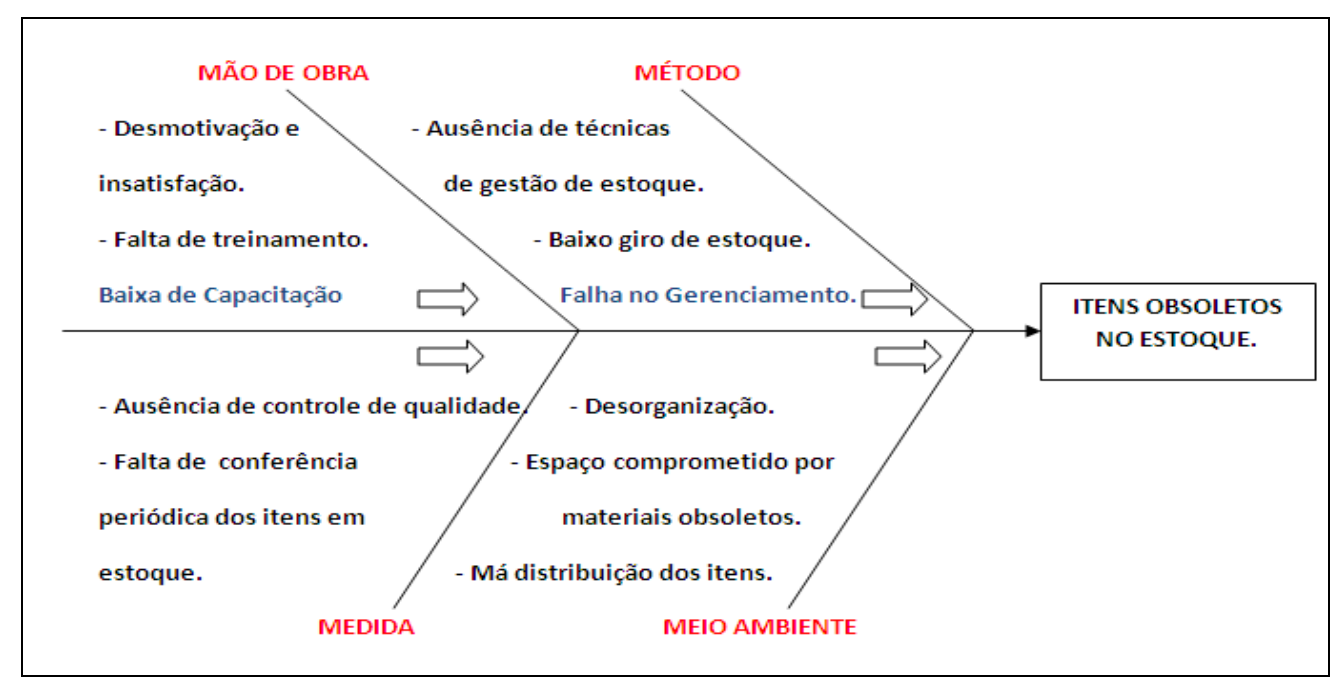

Fonte: Autores (2019)

\subsection{5 $5^{\circ}$ Passo: Elaborar possíveis soluções.}

O Quadro 2 demonstra as possíveis soluções indicadas para as causas levantadas, que são: 
Quadro 2 - Causas e possíveis soluções

\begin{tabular}{|l|l|}
\hline \multicolumn{1}{|c|}{ Causa } & \multicolumn{1}{c|}{ Possiveis Soluções } \\
\hline \multirow{1}{*}{ 1. Baixa Capacitação } & $\begin{array}{l}\text { 1.1 Realizar um treinamento mais específico e técnico } \\
\text { voltado apenas para os gerentes gerais e gerentes de } \\
\text { setores da empresa, para aprimorar as falhas de } \\
\text { conduta na administração e organização. } \\
1.2 \text { Realizar um treinamento mais amplo, menos } \\
\text { técnico, abrangendo todos os funcionários da } \\
\text { empresa, para desde os vendedores até os gerentes, } \\
\text { para que o conhecimento alcançado seja maior. } \\
1.3 \text { Demitir os gerentes atuais e realizar uma nova } \\
\text { contratação de gerentes mais capacitados e } \\
\text { especializados, a fim de apresentar novas soluções e } \\
\text { melhorar os processos organizacionais. Conseguir } \\
\text { um funcionário que seja referência em determinado } \\
\text { assunto pode agregar muito valor para a empresa. }\end{array}$ \\
\hline \multirow{2}{*}{ 2. Desorganização } & $\begin{array}{l}\text { 2.1 Fazer uma conferência periódica de estoque e } \\
\text { aumentar a paletização para que os materiais sejam } \\
\text { organizados por tipo e data. } \\
2.2 \text { Organizar o planejamento de compras por meio } \\
\text { de planilhas. } \\
2.3 \text { Utilizar a tecnologia para adquirir um sistema de } \\
\text { controle de estoque otimizando tempo e processos. }\end{array}$ \\
\hline
\end{tabular}

Fonte: Autores (2019)

\section{$6^{\circ}$ Passo: Avaliar as possíveis soluções}

Para que alguma das soluções possa ser implementada, é necessário avaliá-las nos seguintes fatores: Tecnológico, Econômico, Tempo e Político. O Quadro 3 mostra a avaliação desses fatores.

Quadro 3 - Avaliação dos fatores das possíveis soluções

\begin{tabular}{|c|l|r|r|r|r|r|r|r||}
\hline \hline \multirow{2}{*}{ Solução } & \multicolumn{2}{|c|}{ Tecnológico } & \multicolumn{2}{|c|}{ Econômico } & \multicolumn{2}{|c|}{ Tempo } & \multicolumn{2}{|c|}{ Político } \\
\cline { 2 - 10 } & $\mathrm{S}$ & $\mathrm{N}$ & $\mathrm{S}$ & $\mathrm{N}$ & $\mathrm{S}$ & $\mathrm{N}$ & $\mathrm{S}$ & $\mathrm{N}$ \\
\hline 1.1 & $\mathrm{X}$ & & $\mathrm{X}$ & & $\mathrm{X}$ & & $\mathrm{X}$ & \\
\hline 1.2 & $\mathrm{X}$ & & $\mathrm{X}$ & & & $\mathrm{X}$ & $\mathrm{X}$ & \\
\hline 1.3 & $\mathrm{X}$ & & & $\mathrm{X}$ & & $\mathrm{X}$ & & $\mathrm{X}$ \\
\hline 2.1 & $\mathrm{X}$ & & $\mathrm{X}$ & & $\mathrm{X}$ & & $\mathrm{X}$ & \\
\hline 2.2 & $\mathrm{X}$ & & $\mathrm{X}$ & & $\mathrm{X}$ & & $\mathrm{X}$ & \\
\hline 2.3 & $\mathrm{X}$ & & & $\mathrm{X}$ & $\mathrm{X}$ & & & $\mathrm{X}$ \\
\hline \hline
\end{tabular}

Fonte: Autores (2019)

Posteriormente, foi elaborado um novo resultado mediante os fatores mencionados. O Quadro 4 ilustra essa análise. 
Quadro 4 - Resumo da análise feita

\begin{tabular}{|c|c|}
\hline Solução & Resumo da Análise \\
\hline 1.1 & Nunca foram treinados. \\
\hline 1.2 & $\begin{array}{l}\text { Quanto maior a abrangência melhor, o } \\
\text { que também demanda mais tempo. }\end{array}$ \\
\hline 1.3 & $\begin{array}{l}\text { Trata-se de um bom empregado, } \\
\text { associado ao risco de uma nova } \\
\text { contratação. }\end{array}$ \\
\hline 2.1 & Identificar outras possíveis falhas. \\
\hline 2.2 & $\begin{array}{l}\text { Ter um controle maior dos produtos } \\
\text { obsoletos principalmente (classe A) na } \\
\text { hora de comprar. }\end{array}$ \\
\hline 2.3 & $\begin{array}{l}\text { Custo } \mathrm{x} \text { benefício não é compensador. } \\
\text { Os funcionários também necessitam } \\
\text { saber utilizar o sistema. }\end{array}$ \\
\hline
\end{tabular}

Fonte: Autores (2019)

\section{$7^{0}$ Passo: Decidir solução mais viável a implementar}

Diante das possíveis soluções a serem implementadas, para proporcionar agilidade e segurança ao tomar decisões foi utilizado a Matriz BASICO para a avaliação e priorizar qual solução deverá ser tomada para os respectivos problemas que a empresa vem enfrentando. Lembrando que os critérios são: Benefícios para a organização (B), Abrangência dos resultados (A), Satisfação do Cliente interno (S), e Operacionalidade (O).

\section{$8^{\circ}$ Passo: Implementar Solução}

Neste último passo, será realizado o plano de ação com a ferramenta $5 \mathrm{~W} 2 \mathrm{H}$ onde são tomadas as decisões sobre as principais causas identificadas na fase de análise, como mostra o Quadro 5. 
Quadro 5 - Plano de ação 5W2H

\begin{tabular}{|c|c|c|c|c|c|c|}
\hline O que? & Quem? & Onde? & \begin{tabular}{|l|} 
Quando \\
\end{tabular} & Por que? & Como? & Quanto? \\
\hline What & Who & Where & When & Why & How & How Much \\
\hline Conferência & & & & Melhor & Através & \\
\hline periódica de & & & & rotatividade & da contagem & \\
\hline estoque e & Conferentes. & Estoque. & $20 / 11 / 2019$ & dos produtos & semanal. & Paletes aprox. \\
\hline aumentar a & & & & e evitar custos de & Identificar os & $\mathrm{R} \$ 2.000,00$ reais. \\
\hline \multirow[t]{3}{*}{ paletização. } & & & & \multirow[t]{3}{*}{ produtos parados. } & paletes & \\
\hline & & & & & faltantese & \\
\hline & & & & & comunicar ao gerente. & \\
\hline Realizar um & Gerentes & & & Os gerentes não & Através de cursos & Em média \\
\hline treinamento & (geral e de & Universidade. & $20 / 11 / 2019$ & estão capacitados. & onlines ou & $\mathrm{R} \$ 300,00$ reais. \\
\hline para adquirir & setores). & & & & semipresenciais. & \\
\hline \multicolumn{7}{|l|}{ novos } \\
\hline \multicolumn{7}{|l|}{ conhecimento. } \\
\hline Organizar o & & Empresa e & & Para melhor & Através de & Não informado. \\
\hline planejamento & Gerentes. & estoque. & $20 / 11 / 2019$ & procedimento & planilhas. & \\
\hline de compras. & & & & de compras. & & \\
\hline
\end{tabular}

Fonte: Autores (2019)

Essas modificações no controle de estoque permitem que essas atividades sejam executadas de maneira eficiente e objetiva, possibilitando que seja realizado semanalmente o controle do estoque mínimo e máximo para reposição dos produtos, identificação de sua demanda mensal, gerando o melhor desempenho para empresa das ações internas identificando as principais responsabilidades dos gestores.

\section{Resultados}

A empresa totaliza um capital parado no total de $\mathrm{R} \$ 309.224,90$ reais apenas nos produtos obsoletos durante 1 ano, aplicando a Estrela Decisória alcançou-se o seguinte resultado conforme Tabela 3.

Tabela 3 - Custo x investimento

\begin{tabular}{|c|c|c|c||}
\hline \multicolumn{2}{|c|}{ RESULTADOS ESPERADOS } \\
\hline TOTAL DO CUSTO: & R\$ $309.224,90$ & TREINAMENTO: & R\$ 300,00 por pessoa. \\
\hline \multirow{2}{*}{$\begin{array}{c}\text { TOTAL DO CUSTO APÓS } \\
\text { ESTRELA DECISÓRIA : }\end{array}$} & R\$ $72.624,90$ & TOTAL INVESTIDO: & Aprox. R\$ $2.000,00$ \\
\cline { 2 - 4 } & & & R\$ $18.000,00+2.000,00=20.000,00$ \\
\hline & & Cálculo equivalente a 12 meses. \\
\hline
\end{tabular}

Fonte: Autores (2019) 
Houve uma diminuição de $\mathrm{R}$ \$236.600,00 após a aplicação do método, onde o investimento sairá por $\mathrm{R} \$ 18.000,00$ o custo do treinamento dos cinco gerentes e a paletização no estoque por aproximadamente $\mathrm{R} \$ 2.000,00$ totalizando um valor de $\mathrm{R} \$ 20.000,00$.

\section{Considerações Finais}

O presente estudo de caso teve como objetivo realizar um brainstorming com a equipe de funcionários, identificar através do diagrama de Ishikawa possíveis causas de irregularidades no processo de gerenciamento de estoques, elaborar e analisar a Curva $\mathrm{ABC}$ a fim de identificar e classificar os itens que agregam maior valor monetário e identificar melhorias e oportunidades para tornar o controle de estoque mais eficiente.

Com a utilização da Estrela Decisória e o auxílio das ferramentas da qualidade através dos seus oito passos, foi possível visualizar os materiais obsoletos que causavam maior prejuízo de capital parado na empresa, pois se a gestão de estoque falhar, a empresa deixa de gerar lucros e agregação de valor a este processo. Outro ponto fundamental é a forma como os materiais são armazenados e movimentados, se não for de uma forma adequada acarretará danos aos materiais, em consequência, custo para a empresa. Estoques elevados e mal administrados encarecem o preço final dos produtos, bem como uma aplicação indevida do capital de giro.

Ao final da aplicação da metodologia da Estrela Decisória, foram encontrados resultados satisfatórios, havendo o cumprimento integral de todos os objetivos propostos neste trabalho. Onde houve uma redução significativa dos produtos obsoletos de classe A em 76,51\% equivalente a $\mathrm{R} \$ 236.600,00$ de capital inerte, melhora na organização e capacitação dos funcionários.

Todos os benefícios citados acima vão ao encontro do principal objetivo deste trabalho que é propor uma metodologia capaz de reduzir a quantidade de itens obsoletos do estoque, onde é necessária uma gestão de estoque bem planejada e eficiente, utilizando-se das ferramentas certas para trazer resultados positivos para a instituição.

\section{REFERÊNCIAS}

AMARO, V. Gestão de estoque: um estudo em uma micro empresa do ramo têxtil localizada no interior do Estado de São Paulo. ANAIS DO X SIMPÓSIO DE ENGENHARIA DE PRODUÇÃO (SIMPROD). Sergipe (2018).

ARRUDA, A. I. B.A. et al. Análise da Gestão da Qualidade em uma Indústria de Alimentos em Caruaru - PE: Estudo Sobre a Utilização das Ferramentas da Qualidade. ENEGEP, 2016. 
ARRUDA, A.C.S; RICARDO, E.L; JUDICE, L.V.M.R; JUDICE, J.H; ALMEIDA, D.H. aplicação de ferramentas de qualidade na gestão de estoques em uma empresa distribuidora de medicamentos. ANAIS DO XXXVII ENCONTRO NACIONAL DE ENGENHARIA DE PRODUCAO (ENEGEP). Joinville/ SC 2017.

CARPINETTI, L. C. R. Gestão de Qualidade: conceitos e técnicas. São Paulo: Atlas, 2010.

FERNANDES, L.B; PEREIRA, M.D.G; SACRAMENTO, L.N.S; GURGEL, I.A.G. Decisões sobre a política de estoques. ANAIS DO XXXVI ENCONTRO NACIONAL DE ENGENHARIA DE PRODUCAO. (ENEGEP) João Pessoa/PB 2016.

LOURINHO, A.M; ASSIS, N.S; SILVA, E.B. A importância do controle de estoque para o sucesso de vendas: estudo de caso em uma concessionária de caminhões. ANAIS DO XXXVIII ENCONTRO NACIONAL DE ENGENHARIA DE PRODUCAO. (ENEGEP) Maceió/Al 2018.

MARANHÃO, Mauriti e MACIEIRA, Maria Eliza Bastos. O Processo Nosso de Cada Dia - Modelagem de Processos de Trabalho. $2^{\mathrm{a}}$. ed. Rio de Janeiro: Qualitymark, 2010.

MONTGOMERY, D.C. Introdução ao Controle Estatístico da Qualidade, 7ª ed. Rio de Janeiro: LTC, 2016.

POZO, Hamilton. Administração de recursos materiais e patrimoniais: uma abordagem logística. 3. ed. São Paulo: Atlas, 2007.

OLIVEIRA, Natan Shalom Frutuoso; SANTOS, Marcos dos; MARTINS, Ernesto Rademaker. Aplicação da Matriz BASICO como boa prática de governança em instituições públicas e privadas: Desenvolvimento de um aplicativo de apoio à tomada de decisão. ANAIS DO XIX SIMPÓSIO DE PESQUISA OPERACIONAL E LOGÍSTICA DA MARINHA, Rio de Janeiro/RJ, 2019.

SANTOS, J. L. M; VIANA, J. D.; BERNARDINO, P. E. M.; RIBEIRO, D. C. S.; RAZZINO, C. A. aplicação de ferramentas da gestão de estoques em um supermercado. ANAIS DO XXXVII ENCONTRO NACIONAL DE ENGENHARIA DE PRODUCAO(ENEGEP). Joinville/ SC 2017.

SEBRAE. Manual de Ferramentas da Qualidade, 2005. Disponível em: <http://remonato.pro.br/documents/Manual\%20De\%20Ferramentas\%20Da\%20Qualidade\%20-\%20Sebrae.pdf>. Acesso em: 10 set. 2019.

SILVA, A. V. K. A. M; BELUSSO, B; WERLANG, R. A importância do gerenciamento estratégico do estoque no setor supermercadista. ANAIS DO CURSO DE ENGENHARIA DE PRODUÇÃO. (UCEFF) 2018.

SILVA, G.K.C.B; MATEUS, E.S; SILVA, A.L.G. Análise de sistema de estoques por meio de análise de curva abc e giro de estoque: um estudo de caso numa organização hospitalar pública. ANAIS DO XXXVI ENCONTRO NACIONAL DE ENGENHARIA DE PRODUCAO (ENEGEP) João Pessoa/PB 2016. 